\title{
MISSING CARBON REDUCTIONS? EXPLORING REBOUND AND BACKFIRE EFFECTS IN UK HOUSEHOLDS
}

\author{
Angela Druckman ${ }^{1}$, Mona Chitnis ${ }^{1}$, Steve Sorrell ${ }^{2}$ and Tim Jackson ${ }^{1}$ \\ ${ }^{1}$ ESRC Research Group on Lifestyles, Values and Environment (RESOLVE), University of \\ Surrey, Guildford GU2 7XH, UK. \\ a.druckman@surrey.ac.uk; Tel: +44 (0)1483 686679; Fax: +44 (0)1483 686671 \\ ${ }^{2}$ Sussex Energy Group, University of Sussex, UK.
}

\begin{abstract}
Households are expected to play a pivotal role in reducing the UK's carbon emissions, and the Government is targeting specific household actions as part of its plan to meet the legally binding targets set out in the Climate Change Act 2008. However, by focusing on discrete actions, the Government fails to take account the Rebound Effect - a phenomenon whereby carbon reductions estimated by simple engineering calculations are frequently not realised in practice. For example, installation of loft insulation will most certainly increase the thermal efficiency of homes. But this will free up money that otherwise would be spent by householders on energy bills: this money may then be spent on heating houses to higher temperatures, buying extra furniture, or, say, flying on vacations. Alternatively it may be put into household savings. All of these options give rise to carbon emissions, thus the total carbon saved may be less than predicted. Indeed, in some instances, emissions may even increase - this being known as 'Backfire'.
\end{abstract}

In this paper we estimate the extent of the Rebound Effect under a range of assumptions concerning consumer purchasing decisions, with varying prices, incomes, and savings levels. The paper concludes with a discussion of the policy implications of our findings and provides guidance on the conditions under which Rebound and Backfire can be minimised.

\section{Keywords}

Sustainable consumption, Rebound effect, Backfire, Household consumption, Savings ratio.

Knowledge Collaboration \& Learning for Sustainable Innovation

ERSCP-EMSU conference, Delft, The Netherlands, October 25-29, 2010 


\section{Introduction}

The UK has a target to reduce greenhouse gas (GHG) emissions by at least $80 \%$ below 1990 levels by 2050 (HM Government 2008). It is relying on households to play a pivotal role in meeting this target by stimulating a range of measures including, for example, household energy efficiency improvements.

It is commonly assumed that historical improvements in energy efficiency have reduced energy consumption below the level at it would have been at without those improvements. Nevertheless, such improvements have clearly failed to reduce energy consumption in absolute terms. While the aggregate energy intensity of industrial economies has steadily fallen over the last century, the energy use attributable to UK households has continued to rise, along with the associated carbon emissions (Druckman et al. 2008; Wiedmann et al. 2008; Druckman and Jackson 2009a).

The most common explanation for the failure to decouple energy consumption and carbon emissions from economic growth is that we haven't tried hard enough: energy and carbon prices are too low and policies to encourage energy efficiency and/or lifestyle changes are often small-scale, under-funded, poorly designed and ineffectual. In this view, the appropriate solution is to reinforce these policies - namely, to introduce more regulations, standards, financial support and information programmes alongside the pricing of carbon emissions.

But an additional explanation for the failure to reduce energy consumption is that many of the potential energy savings have been 'taken back' by various behavioural responses which are commonly grouped under the heading of rebound effects. While generally neither anticipated nor intended, these effects reduce the size of the energy savings achieved. An example of a rebound effect would be the driver who replaces a car with a fuel-efficient model, only to take advantage of its cheaper running costs to drive further and more often. In some cases it is even argued that these effects lead to increased energy demand over the long term - an outcome that has been termed 'backfire' (Saunders 1992; Brookes 2000).

Since energy efficiency improvements reduce the effective price of energy services such as travel, the consumption of those services may be expected to increase, thereby offsetting some of the predicted reduction in energy consumption. This so-called direct rebound effect

The 14th European Roundtable on Sustainable Production and Consumption (ERSCP)

The 6th Environmental Management for Sustainable Universities (EMSU) 
was first studied by Khazzoom (1980) and has since been the focus of much research (Greening et al. 2000; Sorrell and Dimitropoulos 2007a; Sorrell and Dimitropoulos 2008; Sorrell et al. 2009). But even if there is no direct rebound effect for a particular energy service (e.g. even if consumers choose not to drive any further in their fuel efficient cars), there are a number of other reasons why the economy-wide reduction in energy consumption may be less than simple 'engineering' calculations suggest. For example, the money saved on motor-fuel consumption may be spent on other goods and services that also require energy to provide. Depending upon the nature, size and location of the energy efficiency improvement, these so-called indirect rebound effects can take a number of forms (Sorrell 2007).

The overall or economy-wide rebound effect from an energy efficiency improvement represents the sum of these direct and indirect effects and is normally expressed as a percentage of the expected energy savings. Hence, an economy-wide rebound effect of $20 \%$ means that one fifth of the potential energy savings are 'taken back' through one or more of the above mechanisms. A rebound effect that exceeds $100 \%$ means that the energy efficiency improvements 'backfire': in other words, they increase overall energy consumption.

The quantification of rebound effects is difficult, owing to limited data, endogenous variables, uncertain causal relationships, trans-boundary effects and other factors (Sorrell 2007). As a result, the existing literature is patchy and most studies focus upon only a subset of the relevant effects measured over relatively short time horizons (Sorrell 2007). While rebound effects are most commonly estimated in relation to energy consumption, they may equally be estimated for carbon emissions or greenhouse gas (GHG) emissions. The percentage effect may not be the same in each case, owing to variations in the energy, carbon and GHG intensity of different goods and services. In this paper, we estimate rebound effects in relation to GHG emissions, since we consider the control of these emissions to be the primary policy goal.

Most studies of rebound effects focus upon household energy services such as heating and lighting and examine the effect of improving the efficiency of delivering those services - for example, using less electricity to provide the same level of lighting through the replacement of incandescent bulbs with compact fluorescents. However, an entirely analogous effect may occur when individuals choose to change their consumption patterns with the primary or

Knowledge Collaboration \& Learning for Sustainable Innovation

ERSCP-EMSU conference, Delft, The Netherlands, October 25-29, 20103 
secondary aim of reducing their environmental impacts or 'carbon footprint'. For example, individuals may choose to walk or cycle rather than using a car, or to turn off the lights in unoccupied rooms. In these circumstances, the money saved by reduced consumption of the relevant energy service(s) will generally be spent on other goods and services that will also be associated with energy consumption and carbon emissions. In other words, there will be indirect rebound effects that will offset some (or in extreme cases all) of the intended energy and emissions savings. However, there will not be any direct rebound effects in these circumstances as the household has voluntarily chosen to consume less of that specific service.

In this paper, reducing consumption of a particular good or service with the primary or secondary aim of reducing environmental impacts is termed an abatement action. This is distinct from improving the efficiency of providing a particular energy service which frequently leads to increased consumption of that service and hence a direct rebound effect. While efficiency improvements lead to both direct and indirect rebound effects, abatement actions lead to only indirect rebound effects. In both cases, these rebound effects are unintended and usually unacknowledged, but their net effect will be to reduce the environmental benefits of the relevant action. Since abatement actions are visible, simple and low cost they are widely promoted by government bodies and non-governmental organisations (NGOs) as an effective means of reducing GHG emissions, as well as being widely practised by individual households. But the indirect rebound effects associated with these actions remain largely unexplored.

This study makes some preliminary estimates of the rebound effects associated with representative abatement actions that may be taken by an average UK household. We consider three actions that have the primary or secondary objective of reducing GHG emissions, namely:

- reducing internal temperatures by $1^{\circ} \mathrm{C}$ by means of lowering the thermostat;

- reducing food purchased by one third by eliminating food waste; and

- walking or cycling instead of using a car for trips of less than 2 miles.

We assume that expenditure avoided due to these actions is either re-spent on other goods and services or is saved. These savings, whether placed in the bank or invested in, for example, government bonds, will also have associated GHG emissions.

The 14th European Roundtable on Sustainable Production and Consumption (ERSCP)

The 6th Environmental Management for Sustainable Universities (EMSU) 
We set up a generalised framework in which we can vary the proportion of avoided expenditure that is re-spent or saved, and also vary the expenditure categories in which the re-spending is carried out. The latter may either be in accordance with the estimated expenditure elasticities for the relevant good or service (see below), or determined exogenously in order to estimate the implications of particular expenditure patterns. In order to reflect the uncertain conditions in the UK economy, our framework also enables investigation of a range of scenarios which have varying assumptions concerning future trends in incomes and prices, and the extent of decarbonisation.

A key feature of this study is that, unlike other rebound studies, it takes account of the impact of household savings and investments. This allows us to model responses in which households behave more frugally, putting aside rather than simply re-spending the money saved through reduced consumption. A further feature of this study is that, for conceptual simplicity, we focus specifically on household actions that do not require capital outlay, removing the requirement to account for the energy investment needed to achieve savings. Finally, we do not take account of price-induced substitution effects.

Our estimates of the extent of the rebound effect are thus deliberately conservative. The rationale for these choices is to produce a transparent study which clearly and simply demonstrates the importance of the rebound effect. Modelling additional dimensions of the rebound effect is the focus of ongoing work.

\section{Background}

Two sets of information are required to estimate the rebound effects from energy efficiency improvements and/or abatement actions by households: First, estimates of the energy consumption and/or GHG emissions that are associated with different categories of household goods and services, and investments; Second, estimates of how the share of expenditure on different goods and services (or investment) varies as a function of prices, income and other variables. The former may be derived from environmentally extended input-output models, life cycle analysis or some combination of the two, while the latter may be derived from the econometric analysis of survey data on household expenditure.

Knowledge Collaboration \& Learning for Sustainable Innovation

ERSCP-EMSU conference, Delft, The Netherlands, October 25-29, 20105 
Econometric models of household behaviour can take a wide range of forms and represent behaviour at varying levels of complexity (Deaton and Muelbauer 1980). Of particular importance is the choice of categories for grouping household expenditure and the level of aggregation of those categories. For example, are all travel-related expenditures grouped into a single category, or is this disaggregated into sub-categories such as petrol, maintenance, public transport and so on? The choice depends upon the nature of the data source, the relevant sample size and the associated degrees of freedom. ${ }^{1}$

While there are quite a few studies estimating the direct rebound effect, estimation of indirect rebound effects appears to be in its infancy, and only a handful of studies that include indirect rebound effects are currently available (Sorrell 2007; Sorrell and Dimitropoulos 2007a; Sorrell 2010). The most widely cited such study is Brännlund et al. (2007) who examine the effect of a $20 \%$ improvement in the 'energy efficiency' of personal transport (all modes) and space heating in Sweden. ${ }^{2}$ They estimate an econometric model of household expenditure on non-durables in which the share of expenditure for thirteen types of nondurable goods or services is expressed as a function of total expenditure on non-durables, the price of each good or service and an overall price index. This allows the own-price, cross-price and expenditure elasticities of each good or service to be estimated. Energy efficiency improvements are assumed to reduce the cost of transport and heating and lead to substitution and income effects that change overall demand patterns (e.g. improvements in transport efficiency are estimated to increase demand for clothes but to decrease demand for beverages). By combining these estimated changes in demand patterns with relevant emission coefficients, Brännlund et al. estimate that energy efficiency improvements in transport and heating lead to total rebound effects (in carbon terms) of $120 \%$ and $175 \%$ respectively (i.e. they backfire). Indeed, their results suggest that the direct rebound effects alone exceed $100 \%$. The latter result appears questionable since it contradicts the results of numerous studies that estimate direct rebound for household energy services to be generally less that 30\% (Sorrell 2007; Sorrell and Dimitropoulos 2007b). Mizobuchi (2008) follows a similar approach to Brännlund et al for Japanese households and finds broadly similar rebound effects, despite important differences in estimation procedures. Neither of these findings take account of capital costs, and when Mizobuchi (2008) extended the study to do so, the rebound effect was estimated to be reduced to around $27 \%$.

\footnotetext{
${ }^{1}$ For example, the UK Living Costs and Food Survey (LCFS) (2008) classifies household consumption into 247 categories using the 'Classification of Individual Consumption According to Purpose' (COICOP) scheme. But these categories are not compatible with categories for which embedded GHG emissions are estimated. Therefore categories are aggregated for empirical work.

${ }^{2}$ Brannlund et al.'s use of the term 'heating' is misleading, since this category actually represents total direct energy consumption and therefore includes non-heating end-uses.
}

The 14th European Roundtable on Sustainable Production and Consumption (ERSCP)

The 6th Environmental Management for Sustainable Universities (EMSU) 
A second Swedish example is Alfredsson (2004) who calculates the direct and indirect energy consequences of 'greener' consumption patterns - including both efficiency improvements, such as buying a more fuel-efficient car, and abatement actions such as car sharing. In the case of greener food consumption (e.g. shifts towards a vegetarian diet), the total energy consumption associated with food items is reduced by around $5 \%$ and total expenditure on food items is reduced by $15 \%$. But the re-spending of this money on a variety of items, notably travel and recreation, leads to indirect energy consumption that more than offset the original energy savings (i.e. backfire). The results for a shift towards 'greener' travel patterns are less dramatic, but the re-spending reduces the overall energy savings by almost one third. A comprehensive switch to green consumption patterns in travel, food and housing is estimated to have a rebound effect of $35 \%$.

In a more recent study, Carlsson-Kanyama et al (2005) used a similar model and approach to Alfredsson, but employing Swedish rather than Dutch data on energy intensity. They found that a shift to 'green' food consumption could reduce overall energy consumption. Closer examination reveals that this result follows largely from the assumption that greener diets are more expensive (owing to the higher cost of locally produced organic food), thereby leading to a negative re-spending effect.

Lenzen and Dey (2002) also explore the consequences of a 'greener diet', but in an Australian context. Their green diet involves less food consumption in weight terms, a $30 \%$ reduction in total food expenditure and significant reductions in food-related energy consumption and GHG emissions. However, once the re-spending effect is allowed for, the net effect is to increase overall energy consumption by 4 to $7 \%$, although GHG emissions are still reduced by around $20 \%$ as a result of reduced livestock emissions. They find that the rebound effect varies from 112 to $123 \%$ for energy consumption and from 45 to $50 \%$ for GHGs.

The results from such studies appear sensitive to the methodology and assumptions used, as well as the types of household analysed and the particular shifts in consumption patterns that are explored. It is evident that the potential for estimating indirect rebound effects has yet to be fully explored and that existing studies differ substantially in terms of data sources, methodology, level of commodity aggregation, technical and/or behavioural changes examined, rebound effects covered, and the magnitude of effects found (Sorrell 2010). In

Knowledge Collaboration \& Learning for Sustainable Innovation 
particular, none of the studies examine the implications of saving or investing the avoided expenditure. Thus, while existing work suggests that indirect rebound effects may sizeable, more studies are required to address methodological weaknesses and to examine a wider range of independent variables.

\section{Methodology}

The approach taken in this study is straightforward. We first identify three possible actions that an average UK household may take to reduce the emissions attributable to its expenditure, based on suggestions from websites sponsored by the UK government ${ }^{3}$. From these we estimate the expected (hoped for) annual reduction in GHG emissions $(\Delta H)$, and approximate annual expenditures $(\Delta \mathrm{a})$ that are likely to be avoided. We assume that the latter are either re-spent on goods and services or saved (invested). This leads to additional GHG emissions $(\Delta G)$ that offset some or all of the anticipated GHG savings $(\Delta H)$. Hence, the actual emission reductions are given by $\Delta \mathrm{H}-\Delta \mathrm{G}$.

We define the rebound effect as:

Rebound $=\frac{\text { Potential savings }- \text { Actual savings }}{\text { Potential savings }}$

And therefore:

Rebound $=\frac{\Delta H-(\Delta H-\Delta G)}{\Delta H}$

Below we outline a general framework for estimating direct and indirect rebound effects due to household GHG abatement actions. As discussed earlier, estimation relies on having information on the GHG intensity of different categories of goods and services, and the expenditure elasticities of those goods and services. In this study we make use of two models designed within RESOLVE ${ }^{4}$ at the University of Surrey. The first is the Surrey Environmental Lifestyle MApping (SELMA) framework from which we obtain GHG intensities. The second is the Econometric Lifestyle Environmental Scenario Analysis (ELESA) model from which we obtain econometric information and estimates of future GHG emissions. These are described below.

\footnotetext{
${ }^{3}$ See www.energysavingtrust.org.uk/; www.actonco2.direct.gov.uk/ and www.lovefoodhatewaste.com.

${ }^{4}$ ESRC Research Group on Lifestyles, Values and Environment.
}

The 14th European Roundtable on Sustainable Production and Consumption (ERSCP)

The 6th Environmental Management for Sustainable Universities (EMSU) 


\subsection{Underlying models: SELMA and ELESA}

SELMA estimates the GHG emissions ${ }^{5}$ that arise in the production and distribution of the goods and services purchased by UK final consumption (households, government and investment). This is known as accounting from the 'consumption perspective'. This perspective is based on the premise that it is the demand for goods and services which drives the production processes that consume resources (including energy resources) and emit pollutants (including carbon dioxide and other GHGs) (UNCED 1992; Daly 1996; UN 2002; HM Government 2005). Using this perspective, estimates include emissions from direct energy use, such as for personal transportation and space heating, as well as 'embedded' emissions, which are the emissions that arise in supply chains in the production and distribution of goods and services purchased in the UK. An important feature of SELMA is that it takes account of all emissions incurred as a result of final consumption in the UK, whether they occur in the UK or abroad. To do this, the estimation of embedded emissions is carried out using a Quasi-Multi-Regional Input-Output (QMRIO) model incorporated within SELMA.

\begin{tabular}{|c|c|c|}
\hline Category & $\begin{array}{l}\text { COICOP } \\
\text { Classification }\end{array}$ & Description \\
\hline 1 & 1 & Food \& non-alcoholic beverages \\
\hline 2 & 2 & Alcoholic beverages, tobacco, narcotics \\
\hline 3 & 3 & Clothing \& footwear \\
\hline 4 & 4.4.1 & Electricity \\
\hline 5 & 4.4.2 & Gas \\
\hline 6 & 4.4.3 & Other fuels \\
\hline 7 & 4.1 to 4.3 & Housing ${ }^{6}$ \\
\hline 8 & 5 & $\begin{array}{l}\text { Furnishings, household equipment \& routine household } \\
\text { maintenance }\end{array}$ \\
\hline 9 & 6 & Health \\
\hline 10 & 7.2.2.1\& 7.2.2.2 & Personal transport fuels \\
\hline 11 & Remainder of 7 & Other transport \\
\hline 12 & 8 & Communication \\
\hline 13 & 9 & Recreation \& culture \\
\hline 14 & 10 & Education \\
\hline 15 & 11 & Restaurants \& hotels \\
\hline 16 & 12 & Miscellaneous goods \& services \\
\hline
\end{tabular}

Details of SELMA's methodology, data sources, assumptions and limitations are provided in Druckman and Jackson (2008; 2009a; 2009b). In the version of SELMA used here,

\footnotetext{
${ }^{5}$ SELMA is a general framework that can be applied to, for example, resource use (such as energy use), carbon dioxide emissions or GHGs. In this study we use results from SELMA in terms of a basket of six GHGs: Carbon dioxide, methane, nitrous oxide, hydro-fluorocarbons, perfluorocarbons and sulphur hexafluoride. These are estimated in units of carbon dioxide equivalent (CO2e) as used in the UK Environmental Accounts (ONS 2008).

${ }^{6}$ This includes household rent, maintenance, repair, and water supply.
} 
emissions attributed to household expenditure are classified in 16 categories based upon the COICOP $^{7}$ classification categories (see Table 1). The rationale for these categories is explained in Druckman and Jackson (2009b). We use the GHG emissions attributed to UK investment final demand ${ }^{8}$ as the general savings category representing household investment $^{9}$. GHG intensities ${ }^{10}$ for each of the 16 expenditure categories, as well as for a general savings category are thus estimated for the time period 1992-2004.

ELESA is an econometric scenario modelling tool in which a Structural Time Series Model (STSM) (Harvey 1989) is used to independently estimate household expenditure equations for each of the 16 categories presented in Table 1, using UK quarterly time series data for 1964:q1 to 2009:q1. This allows examination of the relationship between household expenditure, income, prices, temperature ${ }^{11}$ and a stochastic rather than a deterministic underlying trend, which is arguably important when estimating the elasticities of demand, as discussed by Hunt and Ninomiya (2003). The underlying trends are likely to be strongly affected by technical progress, changes in tastes, consumer preferences, sociodemographic and geographic factors, lifestyles and values, which are not easily measured, and therefore difficult to obtain any suitable data for. The stochastic underlying trends indeed capture the effect of all the Exogenous Non-Economic Factors (ExNEF) (total non-price and non-income effects) mentioned above on expenditure (Chitnis and Hunt 2009b). Historic GHG emissions data (1992-2004) obtained from SELMA are used to model future GHG intensities, again using STSM, as presented in Chitnis and Hunt (2009a), for each of the 16 expenditure categories, and for a general savings category.

ELESA is used to model future GHG emissions for three scenarios (Reference, Low and High):

- 'Reference' Case: This is like a 'business as usual' scenario, where the assumptions for the change in household disposable income, prices (both in constant terms), temperature, EXNEF and carbon intensities represent the 'consensus' or 'most probable' outcomes i.e. resulting in 'business as usual' or 'reference' expenditure (in constant terms) and GHGs.

\footnotetext{
${ }^{7}$ Classification of Individual Consumption According to Purpose (UN 2005).

${ }^{8}$ As noted above, SELMA estimates the GHG emissions attributed to the three components of UK final demand (which is alternatively called consumption): household, investment and government.

${ }_{9}^{9}$ For the purposes of this study, GHG emissions due to investment generated by SELMA and used in ELESA are not attributed to household and government expenditure as in the standard ELESA model. This is because we explore investment explicitly in this study. For more details see Druckman and Jackson (2009b).

${ }^{10}$ GHG intensity of expenditure in each category is defined as GHG attributable to a category divided by expenditure in the same category.

${ }^{11}$ Temperature is included in expenditure equations for electricity, gas and other fuels only.
}

The 14th European Roundtable on Sustainable Production and Consumption (ERSCP) 
- 'Low' Case: Here, household disposable income growth is low, price growth (in constant terms) is high, temperature growth is high, growth in EXNEF is low and carbon intensities are low; i.e. resulting in 'low' growth in expenditure (in constant terms)and GHG emissions.

- 'High' case: Here, household disposable income growth is high, price growth (in constant terms) is low, temperature growth is low, growth in EXNEF is high and carbon intensities growth are high; i.e. resulting in 'high' growth in expenditure (in constant terms) and GHG emissions.

A summary of the assumptions in each of the scenarios is provided in the Appendix. For further information concerning ELESA scenarios the reader is referred to Chitnis et al (2009). ELESA produces estimates for each year up to 2030. The year of focus for this study is 2015.

ELESA models total UK households. In this study, in order to model an average UK household, the results from ELESA in terms of GHG emissions and expenditures are divided by the total number of households in the UK (DCLG 2009: Table 401).

\subsection{GHG abatement actions}

We consider very simple GHG abatement actions advocated by Government sponsored websites in the areas of household energy use, food, and private transportation. These actions are chosen specifically as they do not involve capital expenditure and are therefore simpler to model with fewer assumptions being required than actions that require capital outlay.

\section{a) Household energy reduction}

Many household actions, such as switching off lights in unoccupied rooms, can reduce energy use through simple behavioural changes. Here we use guidance from $\mathrm{ActOnCO}_{2}$ : "Turning your thermostat down by $1^{\circ} \mathrm{C}$ could reduce $\mathrm{CO}_{2}$ emissions and cut your fuel bills by up to 10 per cent' ${ }^{12}$.

\footnotetext{
${ }^{12}$ See http://actonco2.direct.gov.uk/actonco2/home/what-you-can-do/ln-the-home/Reduce-your-CO2-emissions.html. ACT ON $\mathrm{CO}_{2}$ "is a key part of the Government's plan to help tackle [climate change].... The website includes dozens of tips to help people reduce their carbon footprint. ACT ON $\mathrm{CO}_{2}$ is a cross-Government initiative, currently involving the Department of Energy and Climate Change (DECC), the Department for Transport (DfT) and Department for Environment Food and Rural Affairs (DEFRA). This collective approach demonstrates the Government's commitment to taking action on climate change, working with businesses and individuals in order to reduce $\mathrm{CO}_{2}$ emissions". http://actonco2.direct.gov.uk/actonco2/home/aboutus.html Accessed 16.06.10.
}

Knowledge Collaboration \& Learning for Sustainable Innovation 
This estimated reduction is in terms of total household energy usage, but, of course, reducing internal temperatures only effects energy used for space heating. Gas, for example, is used for hot water heating and cooking in addition to space heating, and similarly electricity is also used for lighting, cooking and powering appliances. According to DECC (2009: Table 3.7) in $200768 \%$ of Gas, $12 \%$ of Electricity and $74 \%$ of Other fuels were used for space heating.

Therefore, in order to simulate a $10 \%$ reduction in total household energy bills with the reductions allocated to the portion of each fuel that is devoted to space heating, we reduce expenditure on Gas by $12 \%$, Electricity by $2 \%$, and Other fuels by $13 \%{ }^{13}$. Assuming linearity ${ }^{14}$ between expenditure on fuel and the quantity purchased in line with the $\mathrm{ActOnCO}_{2}$ statement above, we reduce the GHG emissions in each category by the same percentage.

\section{b) Food}

The scope for studying the rebound effect that may arise due to changes in food consumption and diet is very wide, depending on the precise changes made and the level of commodity disaggregation available within the model ${ }^{15}$. As a very simple illustration, we take the broad finding that an average UK household throws away one third of the food purchased $^{16}$ (WRAP 2008). Therefore, we simply assume a reduction in food and nonalcoholic drink expenditure of $33 \%$, and a corresponding $33 \%$ reduction in food and nonalcoholic drink related $\mathrm{GHG}$ emissions.

\section{c) Travel}

Many opportunities are available to reduce expenditure on personal transportation fuels such as through 'smarter driving' techniques or replacing vehicles by more fuel efficient models. Here, we use the example of replacing all journeys under 2 miles that were taken by car by either walking or cycling. Based on data from DfT (2009: Table 3.5) for 2008 we estimate that this would reduce expenditure on personal transportation fuel, as well as the GHG emissions from personal transportation fuel, by $23 \%$.

\footnotetext{
${ }^{13}$ These percentages are calculated based on information in DECC (2009: Table 3.7).

${ }^{14}$ In reality this is not the case for many fuel tariffs in the UK.

${ }^{15}$ For example, livestock have been shown to account for a significant proportion of GHG emissions and therefore a diet with less meat and dairy foods is expected (without taking account of the rebound effect) to result in lower emissions and to produce monetary savings (Garnett 2008; Garnett 2009).

${ }^{16}$ More work has subsequently has been carried out on this topic since the publication of WRAP (2008) disaggregating the types of food wasted by households (WRAP 2009; WRAP 2010). However, to illustrate the rebound effect for the purposes of this study, the broad $1 / 3$ finding is a good start.
}

The 14th European Roundtable on Sustainable Production and Consumption (ERSCP) 


\subsection{Estimating the rebound effect}

In this section we derive an equation for estimating the rebound effect for a household action that has a potential (hoped for) reduction in GHG emissions of $\Delta \mathrm{H}$. This action results in avoided annual expenditure $(\Delta \mathrm{a})^{17}$. We can think of avoided expenditure as being analogous to having extra income. Therefore using symbols that are common practice for economists, let $\Delta \mathrm{a}=\Delta \mathrm{y}$.

We assume that $\Delta y$ can either be re-spent on goods and services in categories 1 to 16 of household expenditure, or it can be saved (invested).

$$
\Delta y=\Delta \exp _{1}+\Delta \exp _{2}+\ldots+\Delta \exp _{16}+\Delta s
$$

or

$$
\Delta y=\sum_{i=1}^{16} \exp _{i}+\Delta s \quad \mathrm{i}=1, \ldots, 16
$$

where $\Delta \exp _{\mathrm{i}}$ is the amount of money re-spent in category $i . \Delta \mathrm{s}$ is the additional money invested.

The change in carbon emissions $\Delta G$ due to the re-spending and change in savings (investments) is given by:

$$
\Delta G=\sum_{i=1}^{16} u_{i} \Delta \exp _{i}+u_{s} \Delta s
$$

where $u_{i}$ is the GHG intensity of expenditure in spending category $i$ and $u_{s}$ is the GHG intensity of investment. ${ }^{18}$

The first task is to work out an expression for $\Delta s$. We do this by referring to a simplified equation for the output of ELESA. ELESA estimates expenditure in each of the 16 extended categories with the remainder of disposable income being saved (invested). This can be written as

\footnotetext{
${ }^{17}$ Note that in this document $\Delta$ stands for changes in variables within the same year.

${ }^{18} \mathrm{GHG}$ intensity of expenditure (investment) is GHGs attributable to each category (investment) divided by expenditure (investment) in the same category.

Knowledge Collaboration \& Learning for Sustainable Innovation ERSCP-EMSU conference, Delft, The Netherlands, October 25-29, 201013
} 
$y=\sum_{i=1}^{16} \exp _{i}+s$

Where $y$ is disposable income, $\exp _{i}$ is expenditure in each category and $s$ is money saved (invested).

Let us define the savings ratio $r$ as the ratio of disposable income $y$ that is put into savings.

$r=\frac{s}{y}$

So the proportion of avoided expenditure that is put into savings is given by:

$$
\Delta s=r \Delta y
$$

Substituting for $\Delta s$ in equation 3 we obtain a relationship that will be used in the next step:

$\sum_{i=1}^{16} \Delta \exp _{i}=(1-r) \Delta y$

The next step is to estimate the amount of money households re-spend in each of expenditure categories 1 to 16. As mentioned above, we can think of the avoided expenditure as being analogous to having extra income. Therefore, holding other variables affecting expenditure constant and using the income elasticity of expenditure $(\beta)$ we can express the change in expenditure for each category due to change in income as:

$$
\Delta \exp _{i}=\beta_{i} \frac{\Delta y}{y} \exp _{i} \quad i=1 \ldots, 16
$$

Substituting for $\Delta \exp _{\mathrm{i}}$ in equation 8 we get:

$$
\frac{\Delta y}{y} \sum_{i=1}^{16} \beta_{i} \exp _{i}=(1-r) \Delta y
$$

Re-arranging:

$$
y=\frac{\sum_{i=1}^{16} \beta_{i} \exp _{i}}{(1-r)}
$$

Substituting for $y$ in equation 9 we have:

The 14th European Roundtable on Sustainable Production and Consumption (ERSCP)

The 6th Environmental Management for Sustainable Universities (EMSU) 


$$
\Delta \exp _{i}=\beta_{i} \frac{(1-r) \Delta y}{\sum_{i=1}^{16} \beta_{i} \exp _{i}} \exp _{i}
$$

Substituting into equation 4 for $\Delta s$ from equation 7 and for $\Delta \exp _{\mathrm{i}}$ from equation 12 we get:

$$
\Delta G=\left(\frac{(1-r) \Delta y}{\sum_{i=1}^{16} \beta_{i} \exp _{i}}\right) \sum_{i=1}^{16} \beta_{i} \exp _{i} u_{i}+r u_{s} \Delta y
$$

Remembering that $\Delta y=\Delta a$ this can be written as

$$
\Delta G=\left(\frac{(1-r) \Delta a}{\sum_{i=1}^{16} \beta_{i} \exp _{i}}\right) \sum_{i=1}^{16} \beta_{i} \exp _{i} u_{i}+r u_{s} \Delta a
$$

This can be used in equation 1 to estimate the rebound effect.

Rebound $=\frac{\Delta G}{\Delta H}$

Therefore the rebound effect can be expressed as

Rebound $=\frac{1}{\Delta H}\left[\left(\frac{(1-r) \Delta a}{\sum_{i=1}^{16} \beta_{i} \exp _{i}}\right) \sum_{i=1}^{16} \beta_{i} \exp _{i} u_{i}+r u_{s} \Delta a\right]$

In summary, equation 16 estimates the rebound effect in terms of:

$\Delta \mathrm{a}$ which is the expenditure avoided by the energy abatement action. This is determined exogenously as explained in Section 3.2.

$\Delta \mathrm{H}$ which is the anticipated $\mathrm{GHG}$ reductions. This is also determined exogenously as explained in Section 3.2.

$r$ which is the savings ratio, defined here as the ratio of disposable income $y$ that is put into savings. The expected savings ratio $r$ is estimated through ELESA. In order to explore the rebound effect in cases of a higher or lower savings ratio, $r$ is adjusted exogenously.

$\exp _{\mathrm{i}}$ which is expenditure in category $i$. This is derived from ELESA. 
$u_{i}$ and $u_{s}$ which are GHG intensities in expenditure category $i$ for investment respectively. These are estimated using ELESA.

$\beta_{i}$ which is the income elasticity of expenditure. This estimated using ELESA.

Equation 16 gives the general case for estimating the rebound effect for both direct and indirect rebound. In this paper we have focused on the indirect rebound effect since direct rebound is less likely in the particular abatement actions we are considering. This is best explained with regard to the food example. Eliminating food waste is assumed to occur by more careful attention to food shopping, budgeting and usage. In these circumstances a simple direct rebound effect is unlikely. In the other two categories, direct rebound on fuels for space heating and personal transport fuels is, in theory, possible but again somewhat counter-intuitive if people are sensitised to demand reduction. If direct rebound were included in these two examples, the overall rebound effect would increase. Our choice to exclude direct rebound is therefore consistent with the nature of giving conservative estimates in this paper.

Accordingly, equation 16 is therefore modified to exclude re-spend in the category in which the action takes place. In the case of the food action, re-spend is not allowed on food. Similarly, for the personal transportation action, re-spend is not allowed on personal transportation fuels. For the household action, re-spend is not allowed on fuel for space heating, but it is allowed to be re-spent on gas for other uses, such for as cooking and hot water heating, and electricity for other uses such as lighting and powering gadgets. In the study we first consider each of the three actions separately, and then in combination. When we then consider them all together, we do not allow re-spend of avoided expenditure on food, transport fuels or fuels for space heating.

\subsection{Estimation of the rebound effect under different conditions}

Using the methodology outlined above, we can estimate the rebound effect for a variety of conditions:

- for each of the three example GHG abatement actions either one at a time or in combination.

- for each of the three ELESA scenarios (High, Reference and Low).

$\circ$ for a variety of savings ratios.

The 14th European Roundtable on Sustainable Production and Consumption (ERSCP)

The 6th Environmental Management for Sustainable Universities (EMSU) 
There is therefore a large combination of possible scenarios for which the rebound effect may be estimated. In this study we focus on combinations that are most realistic, and combinations that are likely to give worst and best (or least bad) case rebound effects.

In order to estimate the most probable size of the rebound effect ELESA's Reference scenario is used, and re-spend is assumed to occur in line with elasticities of expenditure. We refer to this as the 'behaviour as usual' case. The worst rebound effect will occur when all the re-spend is in the most GHG-intensive expenditure category (or invested, if this is more GHG intensive than the most GHG-intensive expenditure category). Conversely, the least bad case rebound effect will occur when all the savings are re-spent on the least GHGintensive expenditure category (or invested, if this is the least GHG-intensive category). In these cases, equation 16 is constrained as appropriate.

The savings ratio $(r)$ is generally estimated through ELESA. However, in order to explore how the rebound effect is influenced by the proportion of avoided expenditure that households place in investments we exogenously change the savings ratio to be the highest and lowest values observed during the last 20 years. We also estimate what the rebound effect would be if all avoided expenditure were to saved.

\section{Results}

\subsection{Household GHG emissions in $\mathbf{2 0 1 5}$}

We first set the scene by examining the estimated expenditure and GHG emissions of an average UK household in 2015 within ELESA's Reference scenario. Figures 1a-1c illustrate that whereas, for example, gas accounts only around $1 \%$ of total expenditure, it is one of the categories with the highest GHG emissions. It is also the most GHG intensive category. The savings category, in contrast, has a relatively low GHG intensity.

Knowledge Collaboration \& Learning for Sustainable Innovation

ERSCP-EMSU conference, Delft, The Netherlands, October 25-29, 201017 
(a)

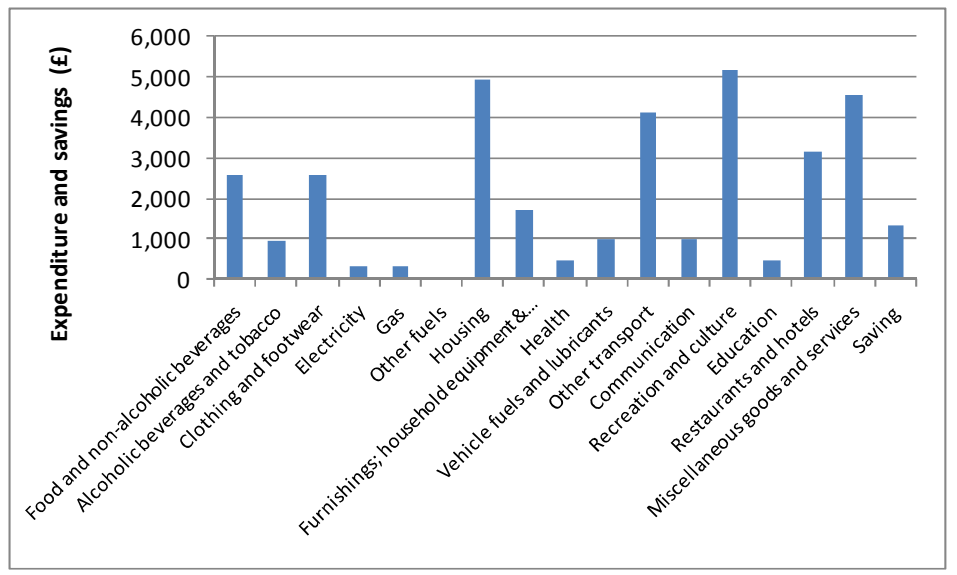

(b)

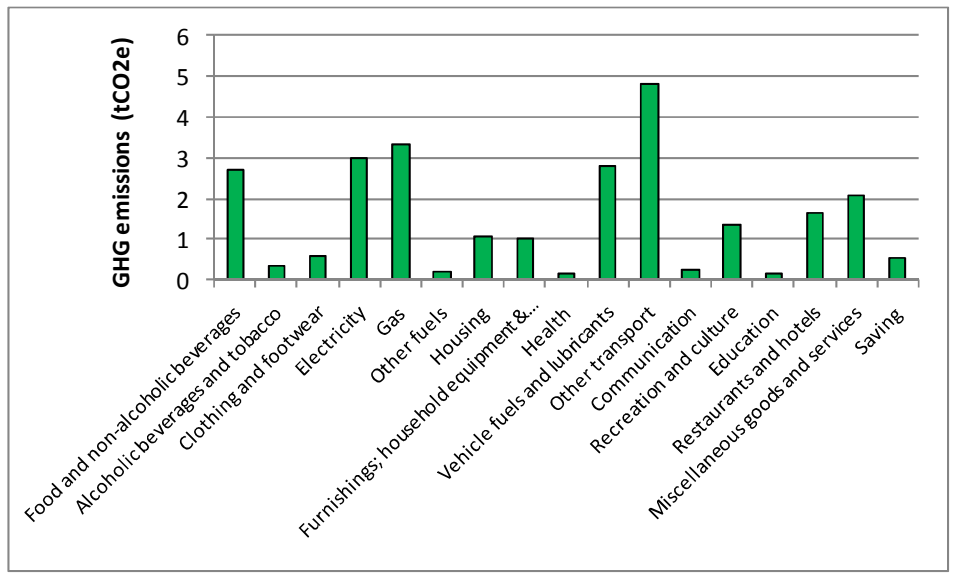

(c)

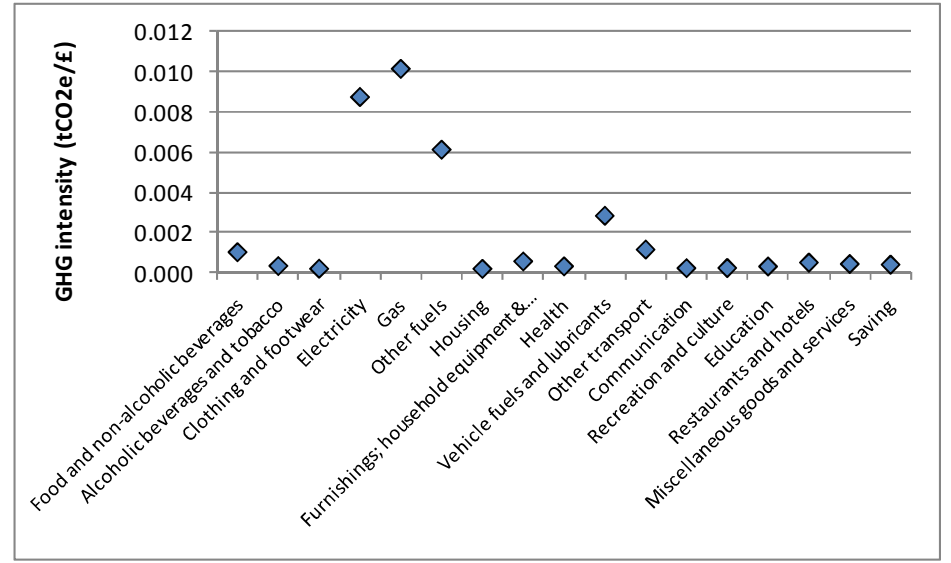

Figure 1. Average annual UK household in ELESA's reference scenario (2015) (a) Expenditure and investment (b) GHG emissions (c) GHG intensities

The 14th European Roundtable on Sustainable Production and Consumption (ERSCP) 


\subsection{Rebound in the Reference Scenario}

The most probable future is presented in the Reference Scenario of ELESA (see Section 3.1). The 'behaviour as usual' rebound is estimated by assuming that avoided expenditure is spent according to income elasticities and invested in line with current investment trends (as given by equation 16). Figure 2 shows the rebound for each of the different abatement actions, and for all the actions carried out in combination. The figure shows the expected (hoped for) GHG emissions $(\Delta \mathrm{H})$ and the emissions due to re-spend/investment of the avoided expenditure $(\Delta G)$. The size of the rebound is a ratio of these two, as given in equation 15.

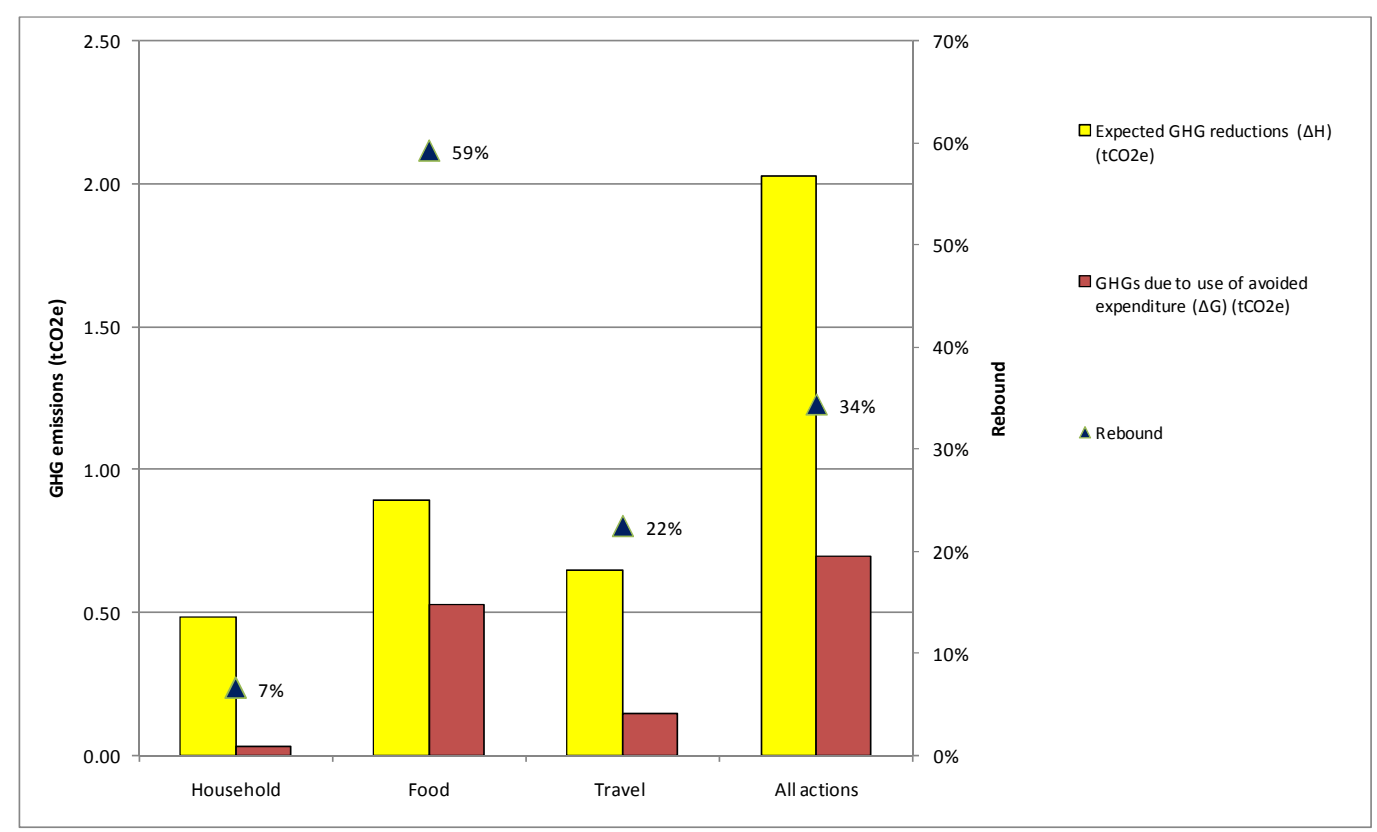

Figure 2. Rebound effect for different actions in the Reference Scenario, 2015

Figure 2 shows that the estimated rebound effect is lowest (7\%) for reducing the household thermostat, and highest (59\%) for reducing food waste. The higher rebound for food is expected as expenditure on food is relatively less GHG intensive than expenditure on household fuels and personal transport fuels, and therefore the re-spend/investment of the avoided expenditure will be relatively more GHG intensive. Where all three GHG abatement actions are assumed to be carried out in combination, the rebound is estimated to be $34 \%$. 
In the discussion which follows we focus on the rebound effect due to all three actions in combination. We next examine how different choices for using the avoided expenditure affect the size of the rebound effect.

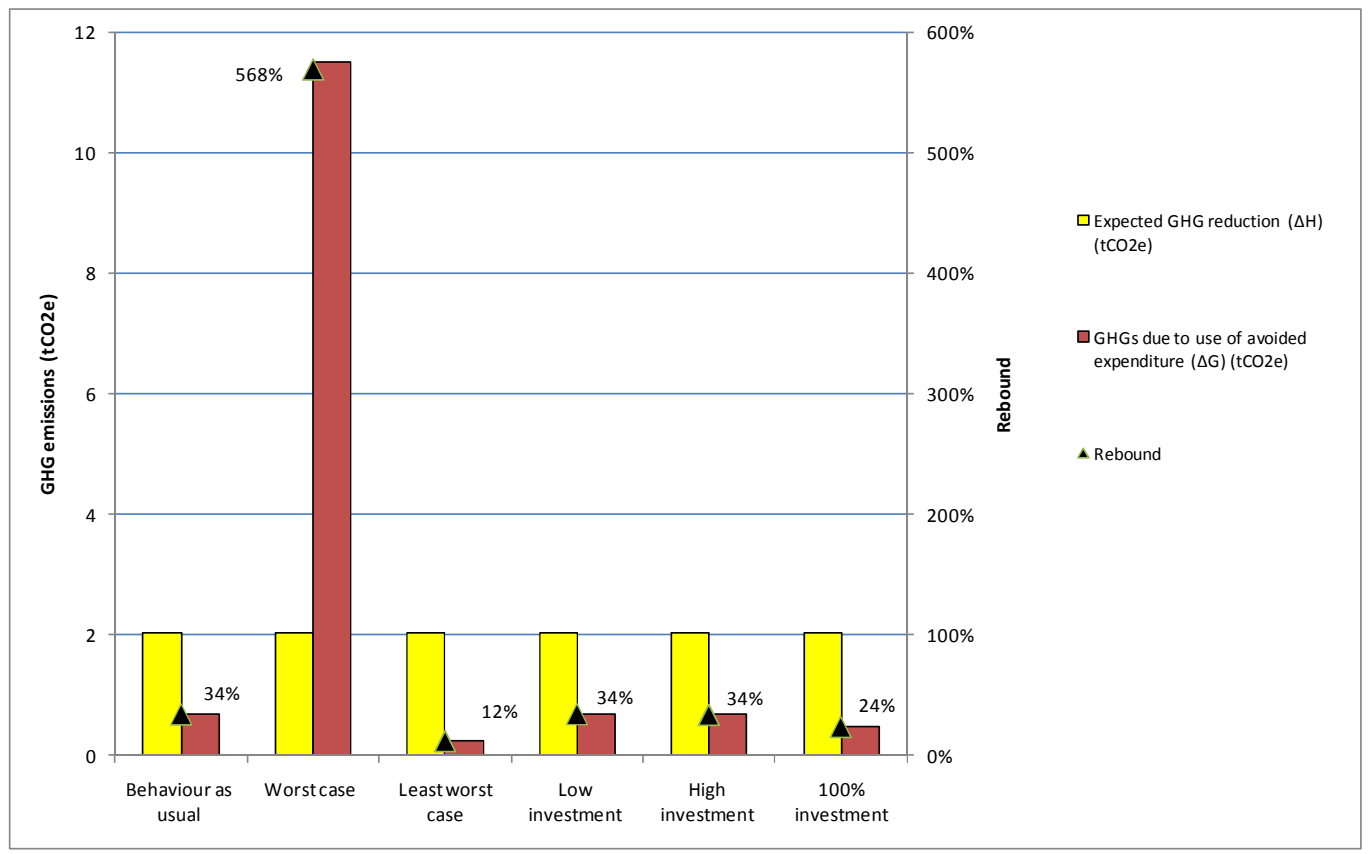

Figure 3. Rebound effect for all actions in the Reference Scenario with varying assumptions concerning re-spend, 2015

One possibility is that households may re-spend all the avoided expenditure in the least GHG intensive category. In ELESA's Reference scenario in 2015 this is 'Housing' ${ }^{\prime 19}$. In this case the rebound effect is estimated to be $12 \%$ which is the 'best' possibility within the Reference scenario (Figure 3). Another possibility is that all the avoided expenditure is spent in the most GHG intensive category which, in the Reference scenario, is gas (this might be used for, say, extra hot showers). In this case the GHG emissions due to the re-spend on gas far outweigh the expected GHG saving from the actions, and rebound of $568 \%$ is estimated (extreme backfire).

The proportion of income that households have invested over the last two decades has varied from around $3 \%$ to $9 \%{ }^{20}$. In the estimates discussed above we have used the household savings ratio ( $r$ ) as forecast by ELESA for 2015 (4\%). In order to investigate how much difference level of $r$ makes, we have exogenously varied $r$. Our estimations show that

\footnotetext{
${ }^{19}$ Housing includes household rent, maintenance, repair and water supply.

${ }^{20}$ The household saving ratio published by the Office for National Statistics differs slightly from our definition in this study (ONS 2010). The ONS make an adjustment for the change in net equity of households in pension funds whereas this adjustment is not carried out in our study.
}

The 14th European Roundtable on Sustainable Production and Consumption (ERSCP)

The 6th Environmental Management for Sustainable Universities (EMSU) 
changing the value of $r$ within this range ( $r=3 \%$ to $r=9 \%)$ has little impact on the rebound effect which remains approximately $34 \%$.

A further possibility is that the avoided expenditure is saved (invested) rather than re-spent. In this case the rebound effect is estimated to be $24 \%$, as indicated by " $100 \%$ investment" in Figure 3. This lower rebound effect is expected as investment (saving) has a relatively low GHG intensity, as shown in Figure 1c.

\subsection{Rebound in different future scenarios}

The estimates of rebound effect discussed so far have all been calculated using the Reference scenario within ELESA. In this section we look the rebound effect in ELESA's Low and High scenarios, again for the suite of three abatement actions taken together.

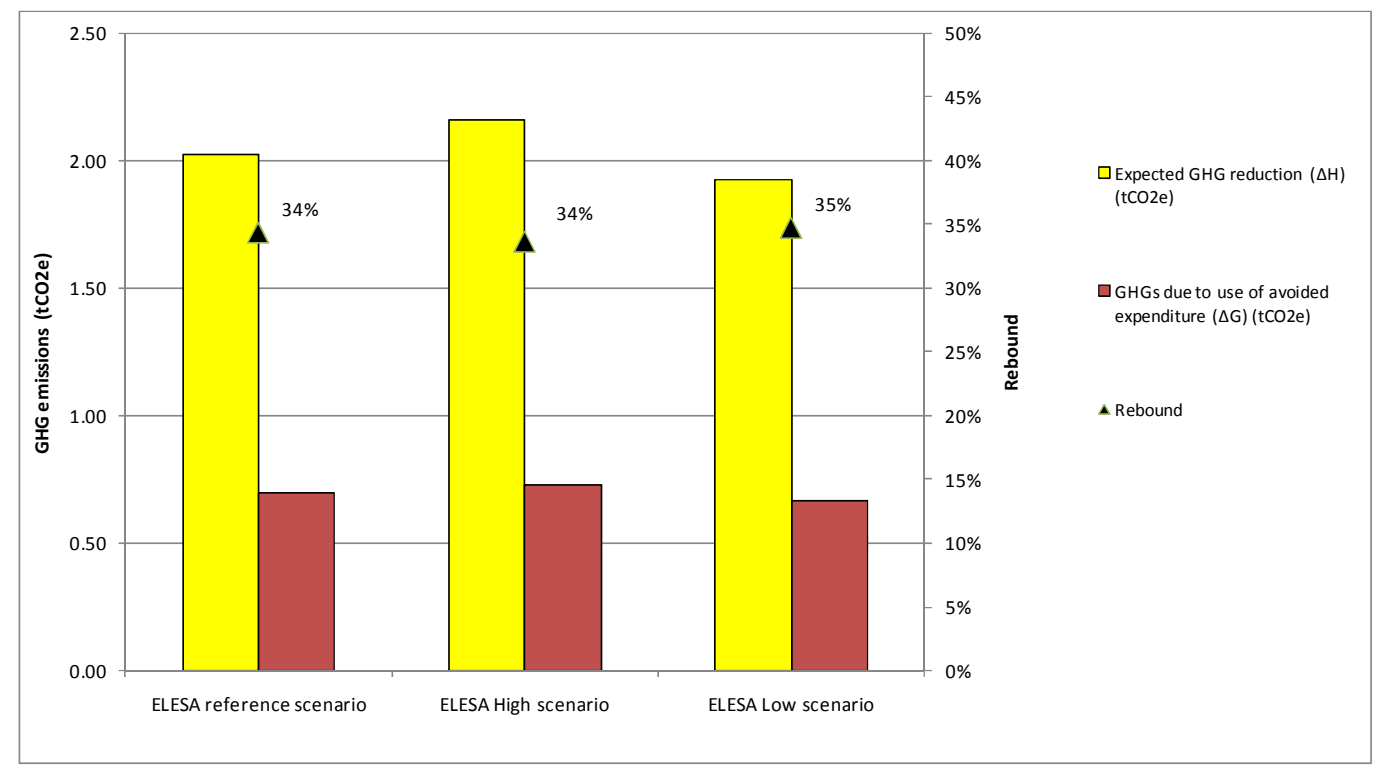

Figure 4. Rebound effect in ELESA's low, high and reference scenarios (2015)

ELESA's High scenario represents a world where disposable incomes are high, prices are low and GHG emissions intensities are also high. In the Low scenario disposable incomes are low, prices are high and GHG emissions intensities are low. Figure 4 shows that the rebound effect does not vary a great deal within these scenarios. 


\subsection{Comparison of results with other studies}

As mentioned above, the size of rebound depends on the precise details of the study. Currently there are very few comparable studies, and those that do exist give widely varying estimates. The closest study to ours is Alfredsson's (2000; 2004) 'greener' consumption study for Sweden. Alfredsson estimated that a comprehensive switch to green consumption patterns in travel, food and housing would have a rebound of $35 \%$. This finding, agrees well with the $34 \%$ estimate in our study for all three abatement actions carried out in combination. However, Alfredsson's study included both direct and indirect rebound effects whereas, by its very nature, our abatement study only involved indirect rebound.

Our study is consistent with others in that it highlights that the rebound effect will be generally be smaller where the abatement action reduces consumption in a highly GHGintensive category, and where the cost savings are re-spent in less GHG intensive categories - and vice versa. There is considerable scope to explore this basic insight further though undertaking more detailed studies.

\section{Limitations of the study}

In this study we have investigated the rebound effect that may arise as a result of three very simple GHG abatement actions that are advocated by the UK government and NGOs. As mentioned above, these have been specifically chosen in this study for their simplicity, in that they do not require household capital expenditure and do not lead to any price-induced substitution effects. This makes estimation of the rebound effect simpler and more transparent. Nevertheless, the study has a number of important limitations.

A major limitation of the study is the relatively small number of expenditure categories modelled. These were based on the 12 major COICOP categories which were then subdivided further to separate out the most important categories in terms of GHG emissions. There is, however, likely to be considerable disparity in the GHG intensities of commodities within each of these categories which could have an important effect on the results. For example, a highly GHG intensive category that we were not able to isolate is personal aviation - which is currently included within the 'Other transport' category. It would be valuable to explore the effects of re-spending within this and similar categories

The 14th European Roundtable on Sustainable Production and Consumption (ERSCP)

The 6th Environmental Management for Sustainable Universities (EMSU) 
A second limitation is the use of 'UK average' households. This precludes investigating how rebound effects vary between different income groups or between groups with different demographic characteristics. Studies of this type need to use more detailed survey data on household expenditures.

A third limitation is that the study neglects other contributing mechanisms to the overall rebound effect - many of which operate over the longer term. For example, if many households carry out the actions modelled, then aggregate demand for gas, electricity, personal transport fuels and food may fall, together with the price of those commodities. This in turn could encourage other households to increase their consumption of these goods and services and thereby increase overall GHGs (Alcott 2008). Capturing these broader price and quantity adjustments requires more sophisticated modelling techniques, such as use of Computable General Equilibrium (CGE) models. However, CGE models, for example, involve more assumptions and are often criticised for lacking transparency (Clarete and Roumasset 1986; Scrieciu 2007). If these rebound effects were to be included, total rebound would increase, and therefore in view of this, our estimate may be considered conservative.

In addition to these limitations, there are also many assumptions and limitations involved in modelling the emissions embedded in goods and services purchased by UK households using SELMA. For details the reader is referred to Druckman et al (2008) and Druckman and Jackson (2009a; 2009b).

Nevertheless, the study demonstrates how the size of the indirect rebound effect depends upon the income elasticities and the relative GHG intensities of different expenditure categories.

\section{Discussion}

The UK Government is relying on actions by households, alongside actions by industry and the Government estate itself, to meet its legally binding carbon reduction target. It is therefore important that policy-makers recognise that only a portion of the GHG emissions reductions that are predicted by 'engineering' calculations will be achieved in reality. This is due to the rebound effect. Our study has aimed to shed some light on the size of this effect for a set of simple GHG abatement actions advocated by Government sponsored websites. These actions have no associated capital costs and are achieved purely through behavioural

Knowledge Collaboration \& Learning for Sustainable Innovation

ERSCP-EMSU conference, Delft, The Netherlands, October 25-29, 201023 
changes. In the interests of simplicity and transparency we have not taken into account economy-wide price effects. These would be expected to increase rebound, and our estimates are therefore, in this respect, conservative.

We find that under conditions of 'behaviour as usual', the rebound effect is around $34 \%$ for the suite of three 'green' household actions' studied (reducing internal temperatures by $1^{\circ} \mathrm{C}$ by means of lowering the thermostat; reducing food purchased by one third by eliminating food waste; and walking or cycling instead of using a car for trips of less than 2 miles). This means that only two thirds of the anticipated GHG emissions reductions are likely to be achieved.

Conditions in future might, of course, be very different, and we therefore investigated the rebound effect in two contrasting scenarios. In one scenario investigated, incomes are high, prices are low and GHG intensity of products and services is high. In a contrasting scenario disposable incomes are low, prices are high and GHG intensity of products and services is low. We found that although the absolute amounts of GHG emissions that are predicted to be saved vary this is largely balanced by the GHG emissions attributed to the re-use (spending or investment) of the avoided expenditure, and that the rebound effect is estimated to remain unchanged at around 34-35\%. The reason for this is that household preferences, as modelled through income elasticities of demand for particular commodities, are assumed to be constant. Our findings demonstrate that so long as household consumption preferences remain unchanged, the rebound effect will be significant. $A$ discussion of possible strategies for changing consumption patterns is beyond the remit of this paper. Suffice to say that possible avenues to achieve this include personal carbon trading or carbon taxation (Kerkhof et al. 2008; Weber and Matthews 2008; Bird and Lockwood 2009; White and Thumin 2009; Bristow et al. 2010; Cohen 2010; Feng et al. 2010). But exogenous shifts in preferences would also change the rebound effect.

Our study also investigated the influence that the relative proportions of disposable income that households choose to spend or save have on the size of the rebound effect. If households were intent on 'green choices' and aware that re-spend of the avoided expenditure gives rise to extra GHG emissions, they might put the money in the bank, unaware that this also has GHG emissions associated with it. Our estimate shows that if all the avoided expenditure were to be invested in general savings such as through bank

The 14th European Roundtable on Sustainable Production and Consumption (ERSCP)

The 6th Environmental Management for Sustainable Universities (EMSU) 
deposit, then the consequence would be to lower the rebound effect to around $24 \%$. Importantly, this estimate assumes the average intensity of UK investments.

A more enlightened household intent on achieving the best outcome might put the expenditure avoided into 'green' investments. Depending on the carbon intensity of the investment chosen, the rebound may in this case approach zero. Furthermore, if the money were invested in ultra low carbon technology, it is possible, in theory, to achieve negative emissions. This would result in a negative rebound effect. In other words, the overall emissions reductions due to the action would be greater than those estimated without taking account of the rebound effect.

It is vital that policy-makers should be aware of the possible best and worst cases. In our estimation the lowest rebound effect that may be hoped for is $12 \%$, meaning that policymakers should be aware that, even under the best conditions, only $88 \%$ of any 'engineering' based calculated GHG emissions reductions might be achieved. This result is, however, highly dependent on the disaggregation of expenditure categories used in the study. Careful use of higher disaggregation would enable isolation of a category of expenditure, such as fine art, that has exceptionally low GHG intensity. If all the re-spend was assumed to be within this category then the rebound might reduce to nearly zero.

The worst case rebound is more serious. We estimate that if households were to spend all the expenditure avoided in the most GHG intensive expenditure category then backfire is highly likely to occur. This means that rather than the hoped for GHG reduction achieved through the household actions, GHG emissions may increase. Our worst case estimate is $568 \%$ rebound, which is extreme backfire. Again this result is highly dependent on the disaggregation of expenditure categories used in the study. Use of higher disaggregation might enable isolation of a category of expenditure that has higher GHG intensity than gas, such as, perhaps, personal aviation. In this case the worst case rebound may be even higher than estimated, and backfire even more severe.

Once aware of it, policy-makers need to be given guidance on how to mitigate the rebound effect. Our study points to two key strategies. First, to encourage households to shift their patterns of consumption to lower GHG intensive categories (Alfredsson 2004). Second, to encourage households to invest in low carbon investments.

Knowledge Collaboration \& Learning for Sustainable Innovation 
In conclusion, it is imperative that policy-makers take account of the rebound effect when estimating GHG emissions reductions achievable through encouraging household behaviour change. If they do not do this, and take steps to reduce rebound, achieving targets to reduce carbon emissions will be even more of a Sisyphean task than it already seems.

\section{Acknowledgements}

The research is supported by funding from the ESRC Research Group on Lifestyles Values and Environment (RESOLVE) (Grant Number RES-152-25-1004) and by funding from the Defra/ESRC/Scottish Government Sustainable Lifestyles Research Group.

\section{References}

Alcott, B., 2008. "The sufficiency strategy: Would rich-world frugality lower environmental impact?" Ecological Economics 64(4): 770-786.

Alfredsson, E. C., 2000. Green Consumption Energy Use and Carbon Dioxide Emission. PhD Thesis, Umeå University.

Alfredsson, E. C., 2004. "'Green" consumption--no solution for climate change." Energy 29(4): 513524.

Bird, J. and M. Lockwood, 2009. Plan B? The prospects for personal carbon trading. London, IPPR.

Brännlund, R., T. Ghalwash and J. Nordström, 2007. "Increased energy efficiency and the rebound effect: Effects on consumption and emissions." Energy Economics 29(1): 1-17.

Bristow, A. L., M. Wardman, A. M. Zanni and P. K. Chintakayala, 2010. "Public acceptability of personal carbon trading and carbon tax." Ecological Economics 69(9): 1824-1837.

Brookes, L. G., 2000. "Energy efficiency fallacies revisited." Energy Policy 28(6-7): 355-366.

Carlsson-Kanyama, A., R. Engström and R. Kok, 2005. "Indirect and Direct Energy Requirements of City Households in Sweden: Options for Reduction, Lessons from Modeling." Journal of Industrial Ecology 9(1): 221-236.

Chitnis, M. and L. C. Hunt, 2009a. What drives the change in UK household energy expenditure and associated $\mathrm{CO} 2$ emissions, economic or non-economic factors? RESOLVE Working Paper 08-09, University of Surrey, UK. Available from http://www.surrey.ac.uk/resolve/Docs/WorkingPapers/RESOLVE WP 08-09.pdf.

Chitnis, M. and L. C. Hunt, 2009b. Modelling UK household expenditure: economic versus noneconomic drivers. RESOLVE Working Paper 07-09., University of Surrey, UK. Available from http://www.surrey.ac.uk/resolve/Docs/WorkingPapers/RESOLVE WP 07-09\%20.pdf.

Chitnis, M., A. Druckman, L. Hunt, S. Milne and T. Jackson, 2009. Analysing the Role of Lifestyles in Determining UK Household Energy Demand and GHG Emissions: Predictions and Scenarios to 2050. Conference on Energy Economics and Technology. Long-term Energy Trends Where will we be in 2050?, Dresden, Germany.

The 14th European Roundtable on Sustainable Production and Consumption (ERSCP)

The 6th Environmental Management for Sustainable Universities (EMSU) 
Clarete, R. L. and J. A. Roumasset, 1986. "CGE Models and Development Policy Analysis: Problems, Pitfalls, and Challenges." American Journal of Agricultural Economics 68(5): 1212-1216.

Cohen, M. J., 2010. "Is the UK preparing for "War"? Military metaphors, personal carbon allowances, and consumption rationing in historical perspective." Climatic Change.

Daly, H., 1996. Beyond Growth - The Economics of Sustainable Development. Boston, MA., Beacon Press

DCLG. 2009. "Live tables on household estimates and projections." Accessed 10.03.10, from http://www.communities.gov.uk/housing/housingresearch/housingstatistics/housingstatisticsby householdestimates/livetables-households/.

Deaton, A. and J. Muelbauer, 1980. Economics and Consumer Behaviour. Cambridge, UK, Cambridge University Press.

DECC. 2009. "Energy Consumption in the UK. Domestic Data Tables 2009 update." Accessed 09.03.10, from http://www.decc.gov.uk/en/content/cms/statistics/publications/ecuk/ecuk.aspx.

DfT. 2009. "National Travel Survey: 2008." Accessed 02.06.10, from http://www.dft.gov.uk/pgr/statistics/datatablespublications/personal/mainresults/nts2008/.

Druckman, A. and T. Jackson, 2008. The Surrey Environmental Lifestyle MApping (SELMA) framework: development and key results to date. RESOLVE Working Paper 08-08, University of Surrey, Guildford, UK. Available from http://www.surrey.ac.uk/resolve/Docs/WorkingPapers/RESOLVE WP 08-08.pdf.

Druckman, A. and T. Jackson, 2009a. "The carbon footprint of UK households 1990-2004: a socioeconomically disaggregated, quasi-multiregional input-output model." Ecological Economics 68 (7): 2066-2077.

Druckman, A. and T. Jackson, 2009b. Mapping our carbon responsibilities: more key results from the Surrey Environmental Lifestyle MApping (SELMA) framework. RESOLVE Working Paper 0209, University of Surrey, Guildford, UK. Available from http://www.surrey.ac.uk/resolve/Docs/WorkingPapers/RESOLVE WP 02-09.pdf.

Druckman, A., P. Bradley, E. Papathanasopoulou and T. Jackson, 2008. "Measuring progress towards carbon reduction in the UK " Ecological Economics 66(4): 594-604.

Feng, K., K. Hubacek, D. Guan, M. Contestabile, J. Minx and J. Barrett, 2010. "Distributional Effects of Climate Change Taxation: The Case of the UK." Environ. Sci. Technol.

Garnett, T., 2008. "Cooking up a storm: Food, greenhouse gas emissions and our changing climate." Accessed 15.06.09, from http://www.fcrn.org.uk/frcnPubs/publications/PDFs/CuaS web.pdf.

Garnett, T., 2009. "Livestock-related greenhouse gas emissions: impacts and options for policy makers." Environmental Science \& Policy 12(4): 491-503.

Greening, A. L., D. L. Greene and C. Difiglio, 2000. "Energy efficiency and consumption -- the rebound effect -- a survey." Energy Policy 28(6-7): 389-401.

Harvey, A. C., 1989. Forecasting, structural time series models and the Kalman filter Cambridge Cambridge University Press.

HM Government, 2005. Securing the future: delivering UK sustainable development strategy. London, UK, TSO (The Stationery Office).

HM Government, 2008. Climate Change Act 2008. London, UK, The Stationery Office Limited.

Knowledge Collaboration \& Learning for Sustainable Innovation

ERSCP-EMSU conference, Delft, The Netherlands, October 25-29, 201027 
Hunt, L. and Y. Ninomiya, 2003. "Unraveling Trends and Seasonality: A Structural Time Series Analysis of Transport Oil Demand in the UK and Japan." Energy Journal 24(3): 63.

Kerkhof, A. C., H. C. Moll, E. Drissen and H. C. Wilting, 2008. "Taxation of multiple greenhouse gases and the effects on income distribution: A case study of the Netherlands." Ecological Economics 67(2): 318-326.

Khazzoom, J. D., 1980. "Economic implications of mandated efficiency in standards for household appliances." Energy Journal 1(4): 21-40.

Lenzen, M. and C. J. Dey, 2002. "Economic, energy and greenhouse emissions impacts of some consumer choice, technology and government outlay options." Energy Economics 24(4): 377403.

Mizobuchi, K., 2008. "An empirical study on the rebound effect considering capital costs." Energy Economics 30(5): 2486-2516.

ONS. 2008. "Environmental Accounts." Accessed 07.11.08, from http://www.statistics.gov.uk/statbase/explorer.asp?CTG $=3 \& S L=\& D=4261 \& D C T=32 \& D T=32 \#$ $\underline{4261 .}$.

ONS. 2010. "Household Saving Ratio." Accessed 08.02.10, from http://www.statistics.gov.uk/StatBase/Analysis.asp?vlnk=91\&Pos=\&ColRank=1\&Rank=320.

Saunders, H. D., 1992. "The Khazzoom-Brookes Postulate and Neoclassical Growth." The Energy Journal 13(4): 131.

Scrieciu, S. S., 2007. "The inherent dangers of using computable general equilibrium models as a single integrated modelling framework for sustainability impact assessment. A critical note on Bohringer and Loschel (2006)." Ecological Economics 60(4): 678.

Sorrell, S., 2007. The rebound effect: an assessment of the evidence for economy-wide energy savings from improved energy efficiency. London, UK, UKERC.

Sorrell, S., 2010. Mapping rebound effects from sustainable behaviours: key concepts and literature review. Brighton, Sussex Energy Group, SPRU, University of Sussex.

Sorrell, S. and J. Dimitropoulos, 2007a. UKERC Review of evidence for the rebound effect: Technical Report 2: Econometric studies. London, UK Energy Research Centre.

Sorrell, S. and J. Dimitropoulos, 2007b. UKERC Review of evidence for the rebound effect: Technical Report 2: Econometric studies. London, UK Energy Research Centre.

Sorrell, S. and J. Dimitropoulos, 2008. "The rebound effect: Microeconomic definitions, limitations and extensions." Ecological Economics 65(3): 636-649.

Sorrell, S., J. Dimitropoulos and M. Sommerville, 2009. "Empirical estimates of the direct rebound effect: A review." Energy Policy 37(4): 1356-1371.

UN, 2002. Report of the World Summit on Sustainable Development: Johannesburg, South Africa, 26 August-4 September 2002.

UN, 2005. Classification of Individual Consumption According to Purpose, (COICOP). United Nations Statistics Division.

UNCED, 1992. "Agenda 21". Rio de Janeiro, Brazil, 3-14 June 1992., United Nations Conference on Environment and Development.

The 14th European Roundtable on Sustainable Production and Consumption (ERSCP)

The 6th Environmental Management for Sustainable Universities (EMSU) 
Weber, C. L. and H. S. Matthews, 2008. "Quantifying the global and distributional aspects of American household carbon footprint." Ecological Economics 66(2-3): 379-391.

White, V. and J. Thumin, 2009. Moderating the distributional impacts of personal carbon trading. Bristol, UK, CSE.

Wiedmann, T., R. Wood, M. Lenzen, J. Minx, D. Guan and J. Barrett, 2008. Development of an Embedded Carbon Emissions Indicator - Producing a Time Series of Input-Output Tables and Embedded Carbon Dioxide Emissions for the UK by Using a MRIO Data Optimisation System, Report to the UK Department for Environment, Food and Rural Affairs by Stockholm Environment Institute at the University of York and Centre for Integrated Sustainability Analysis at the University of Sydney, June 2008. Defra, London, UK.

WRAP, 2008. The food we waste. Banbury, Oxon, Waste and Resources Action Programme.

WRAP. 2009. "Household food and drink waste in the UK." Accessed 22.04.10, from http://www.wrap.org.uk/downloads/Household food and drink waste in the UK report.5e9175bf.8048.pdf.

WRAP. 2010. "Waste arisings in the supply of food and drink to households in the UK." Accessed 12.04.10, from http://www.wrap.org.uk/downloads/RSC002005 March 252010 FINAL.a3201b13.8904.pdf. 


\section{Appendix. Summary of assumptions in ELESA scenarios.}

Table 1: Real household disposable income growth rate assumptions in ELESA Scenarios (2015)

\begin{tabular}{|c|c|c|c|}
\hline & Low & Reference & High \\
\hline & \% p.a. & \% p.a. & $\%$ p.a. \\
\hline $\begin{array}{c}\text { Real household disposable income } \\
\text { growth rate assumptions }\end{array}$ & 2.00 & 2.50 & 3.00 \\
\hline
\end{tabular}

Table 2: Real price growth rate assumptions in ELESA Scenarios (2015)

\begin{tabular}{|l|r|r|r|}
\hline Category & \multicolumn{1}{|c|}{ Low } & \multicolumn{1}{|c|}{ Reference } & High \\
\hline & \% p.a. & \% p.a. & $\%$ p.a. \\
\hline Food and non-alcoholic beverages & -1.50 & -1.00 & -0.50 \\
\hline Alcoholic beverages and tobacco & 1.25 & 1.75 & 2.25 \\
\hline Clothing and footwear & -4.50 & -4.00 & -3.50 \\
\hline Electricity & 3.17 & 2.86 & 3.70 \\
\hline Gas & 3.27 & 3.00 & 4.05 \\
\hline Other fuels & 3.00 & 3.50 & 4.00 \\
\hline Other housing & 3.00 & 3.50 & 4.00 \\
\hline Furnishings; household equipment \& routine maintenance of the house & -1.75 & -1.25 & -0.75 \\
\hline Health & 0.25 & 0.75 & 1.25 \\
\hline Vehicle fuels and lubricants & 0.88 & 0.39 & 1.36 \\
\hline Other transport & -0.50 & 0.00 & 0.50 \\
\hline Communication & -4.25 & -3.75 & -3.25 \\
\hline Recreation and culture & -2.00 & -1.50 & -1.00 \\
\hline Education & 3.00 & 3.50 & 4.00 \\
\hline Restaurants and hotels & 0.75 & 1.25 & 1.75 \\
\hline Miscellaneous goods and services & -0.45 & 0.05 & 0.55 \\
\hline
\end{tabular}

For further details please see Chitnis et al (2009).

The 14th European Roundtable on Sustainable Production and Consumption (ERSCP)

The 6th Environmental Management for Sustainable Universities (EMSU) 